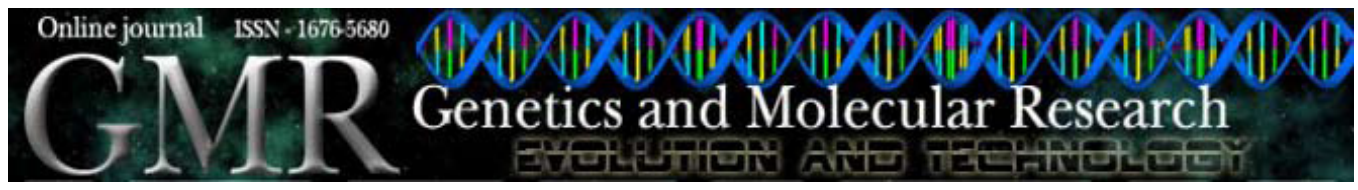

\title{
Genetics of quantitative and qualitative traits of isabgol (Plantago ovata)
}

\author{
N. Singh and R.K. Lal \\ Department of Genetics and Plant Breeding/Planting Material and \\ Varieties Development, Central Institute of Medicinal and \\ Aromatic Plants, Lucknow, India \\ Corresponding author: R.K. Lal \\ E-mail: rk.lal@cimap.res.in
}

Genet. Mol. Res. 8 (3): 939-950 (2009)

Received December 17, 2008

Accepted May 28, 2009

Published August 11, 2009

\begin{abstract}
Isabgol is a medicinal plant known for its high-quality dietary fiber. The genetics and inheritance of economic characters, such as number of panicles, panicle length, seed yield, and swelling factor, were measured by diallel analysis of $F_{1}$ progenies from seven parents. The additive component of genetic variance was significant for days to flowering, plant height, branches/plant, peduncle length, panicle length, days to maturity, and swelling factor, whereas the dominance component of genetic variance was significant for all the characters except panicles/plant. Additivity was not significant for all the characters, indicating absence of non-allelic interactions (epistasis) in controlling gene expression. Heritability in the narrow sense was very high for panicle length, days to flowering, and plant height, and moderate for branches/plant, panicles/plant, days to maturity, seed yield, husk yield, and swelling factor. However, the degree of genetic improvement was only high for panicle length, seed yield and husk yield. We conclude that hybridizations, isolation
\end{abstract}


of superior genotypes by sib selection and recurrent selection, and exploitation of hybrid vigor in specific parental-cross combinations are good strategies for isabgol crop improvement.

Key words: Allelic interactions; Diallel analysis; Epistasis; Genetic improvement; Heterozygosity; Over-dominance

\section{INTRODUCTION}

The genus Plantago (family: Plantaginaceae) comprises 200 species, of which 10 occur in India (Anonymous, 1969). Among the latter, Plantago ovata F is valued for its seeds and husk, which have been used in the indigenous medicine for many centuries all over the world. The seeds and husk of $P$. ovata are used in both traditional and modern medicine. Seeds are used for cooling, as a demulcent, in inflammatory and bilious derangement of the digestive organs, applied as a poultice to rheumatic and gouty swellings, in dysentery and for irritation of the intestinal tract; the decoction is used for cough and chronic diarrhea. The husk from the seed has the property of absorbing and retaining water, and hence, it works as an anti-diarrheal drug. Improved yield is one of the important goals of plant breeders. Success in plant improvement has over the years accrued through a judicious application of a number of genetic principles. One of the important reasons for nearly stagnant yields of isabgol may be limited genetic improvement. This might have been due to a narrow genetic base and use of traditional breeding techniques with little or no understanding of the genetic architecture of the target populations. It is essential to understand the nature and magnitude of gene action involved in the inheritance of seed yield and associated characters. The present investigation was, therefore, conducted to understand the genetic architecture of economic characters, in order to identify highly divergent parents. A diallel analysis (Hayman, 1954a,b) was carried out to characterize the nature and magnitude of gene effects for yield and its components and to select parents for an effective hybridization program.

\section{MATERIAL AND METHODS}

The experimental material comprised 49 genotypes, including $21 \mathrm{~F}_{1}$ plants, 21 reciprocals and 7 parents (three generations selfed). Parents were homozygous as they were selfpollinated for few generations and selected on the basis of morphological metric traits and numbered $\mathrm{P}_{1}$ to $\mathrm{P}_{7}$ (Table 1; Figure 1).

Table 1. Salient features of seven parental genotypes in Plantago ovata.

\begin{tabular}{ll}
\hline Parents & Salient features \\
\hline P1 & Normal and long panicle, medium broad leaves, early flowering, high seed yielder \\
P2 & Branched and small panicle, broad leaves, late flowering \\
P3 & Feathery and small panicle, thin and narrow leaves, very early flowering \\
P4 & Club shaped and small panicle, broad leaves, very late flowering, low seed yielder, high swelling factor \\
P5 & Normal panicle, Niharika (variety used as check), medium panicle, medium broad leaves, early flowering \\
P6 & Club shaped and medium panicle, very broad leaves, late flowering, high swelling factor \\
P7 & Cottony long and very long panicle, broad leaves, late flowering \\
\hline
\end{tabular}




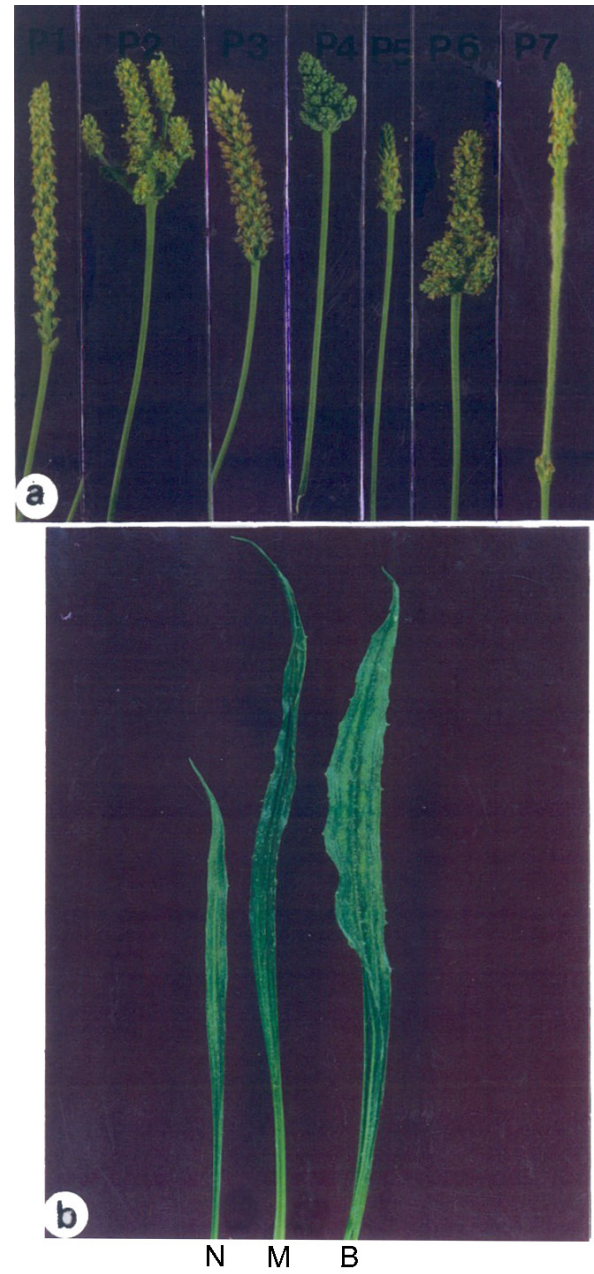

Figure 1. a. Morphological variations in panicles among the Plantago ovata accessions. P1 = Normal; P2= branched; P3 = feathery; P4 = club; P5 = normal (control); P6 = club; P7 = cottony long. b. Variation in leaves of diferrent parents. $\mathrm{N}=$ narrow; $\mathrm{M}=$ medium; $\mathrm{B}$ = broad. See Table 1 , for complementary explanation.

Forty-two hybrids were developed in diallel fashion ( 7 x 7) during February to March 1998 and evaluated in the yield evaluation trials. The seven parents with 42 hybrids were sown using a randomized block design replicated twice (November to April 1998-1999). Plot size for each treatment was one row of $3 \mathrm{~m}$ in length with $10 \times 30 \mathrm{~cm}$ plant to plant and row to row spacing. The crop was fertilized with $60 \mathrm{~kg} \mathrm{~N}, 30 \mathrm{~kg} \mathrm{P}_{2} \mathrm{O}_{5}$ and $30 \mathrm{~kg} \mathrm{~K} 2 \mathrm{O}$ per hectare. Data were recorded on five competitive randomly selected plants in each line for the 10 morphometric traits: days to flowering, plant height $(\mathrm{cm})$, branches/plant, panicles/plant, peduncle length $(\mathrm{cm})$, panicle length $(\mathrm{cm})$, days to maturity, seed yield, husk yield, and swelling factor (volume of soaked water $(\mathrm{mL})$ by the seeds/amount of seeds $(\mathrm{g})$ ). 
Mean data were subjected to statistical analysis by the Hayman model (Hayman, 1954a,b, 1958) using a computer program package developed at the Data Processing Division of the CIMAP, Lucknow, which was based on the work of Singh and Chaudhary (1979) and Sharma (1998). Calculation of genetic advance was based on the formula given by Allard (1960).

\section{RESULTS}

The $t^{2}$ test of additivity was not significant for all the characters except days to flowering, which was significant at the $5 \%$ level but not significant at the $1 \%$ level, indicating the absence of non-allelic interactions (epistasis) in controlling gene expression (Table 2). Thus, the absence of epistasis primarily confirmed the adequacy of Hayman's additive model for the analysis of genetic variance and associated parameters. The additive component $\left({ }^{\wedge} \mathrm{D}\right)$ of genetic variance was significant for days to flowering, plant height, branches/plant, peduncle length, panicle length, days to maturity, and swelling factor, whereas the dominance component $\left(\hat{\mathrm{H}}_{1}\right)$ of genetic variance was significant for all the characters except panicles/plant (Table 3). The overall dominance effect was determined by $\hat{\mathrm{h}}_{2}$ estimates giving the total sum over all the loci in a heterozygous state. This was positive and significant for plant height, panicle length, seed and husk yield. The non-significant $\hat{\mathrm{h}}_{2}$ estimates were observed for days to flowering, branches/plant, panicles/plant, peduncle length, days to maturity, and swelling factor. The estimates of $\hat{H}_{1}$ were higher than estimates of $\hat{h}_{2}$ for all the characters. The estimates for F-components were positive and significant for days to flowering and days to maturity, suggesting an excess of positive genes controlling these characters (Table 3). Degree of dominance $\left(\hat{H}_{1} / \mathrm{D}\right)^{0.5}$ was higher than unity for panicles/plant, peduncle length, seed yield, husk yield, and swelling factor, suggesting that these characters were under the influence of over dominance. The degree of dominance for days to flowering, plant height, branches/plant, panicle length, and days to maturity was less than unity, suggesting partial dominance for these characters (Table 2). The estimates of the ratio $\hat{\mathrm{H}}_{2} / 4 \hat{\mathrm{H}}_{1}$ were close to the expected value of 0.25 for branches/plant, panicles/plant, and panicle length suggesting symmetrical distribution of positive and negative dominant genes in parents. For days to flowering, plant height, peduncle length, days to maturity, seed yield, husk yield, and swelling factor, it was far from the expected value, revealing an asymmetrical distribution of positive and negative genes among the parents. This was also corroborated by the correlation between parental order of dominance $(\mathrm{Wr}+\mathrm{Yr})$ and parental measurement (Yr), which suggests that negative genes were more frequent than the positive genes in parents as the negative $r$ values for most of the characters. The positive $r$ values for branches/ plant and days to maturity indicated positive effects of the alleles controlling these traits. The ratio $\left(4 \mathrm{DH} \hat{H}_{1}\right)^{0.5}+\mathrm{F} /\left(4 \mathrm{DH} \hat{H}_{1}\right)^{0.5}-\mathrm{F}$, which gives the relative value of dominant and recessive genes, was greater than unity for days to flowering, plant height, peduncle length, panicle length, days to maturity, swelling factor. It was less than one for branches/plant, panicles/plant, seed yield, and husk yield. The measurement of completely dominant or recessive parents may not be predicted reliably for any of the traits, as the $\mathrm{r}^{2}$ values were considerably less than 1 . The ratio $\hat{\mathrm{h}}_{2} / \hat{\mathrm{H}}_{2}$ denotes an approximate number of genes or groups of genes controlling the characters, exhibiting dominance, and was less than one for all the characters except panicle length (Table 2). Narrow sense heritability estimates $\hat{h}^{2}(\mathrm{~ns})$ ranged from $24.3 \%$ for peduncle length to $74 \%$ for panicle length. It was high for panicle length, days to flowering and plant height. Other characters were moderately heritable, whereas $\hat{\mathrm{h}}^{2}$ (ns) for peduncle length was low. Genetic advance ranged from $4.93 \%$ (for days to maturity) to $64.67 \%$ (for seed and husk yield) (Table 2). 
Genetics of quantitative and qualitative traits of isabgol

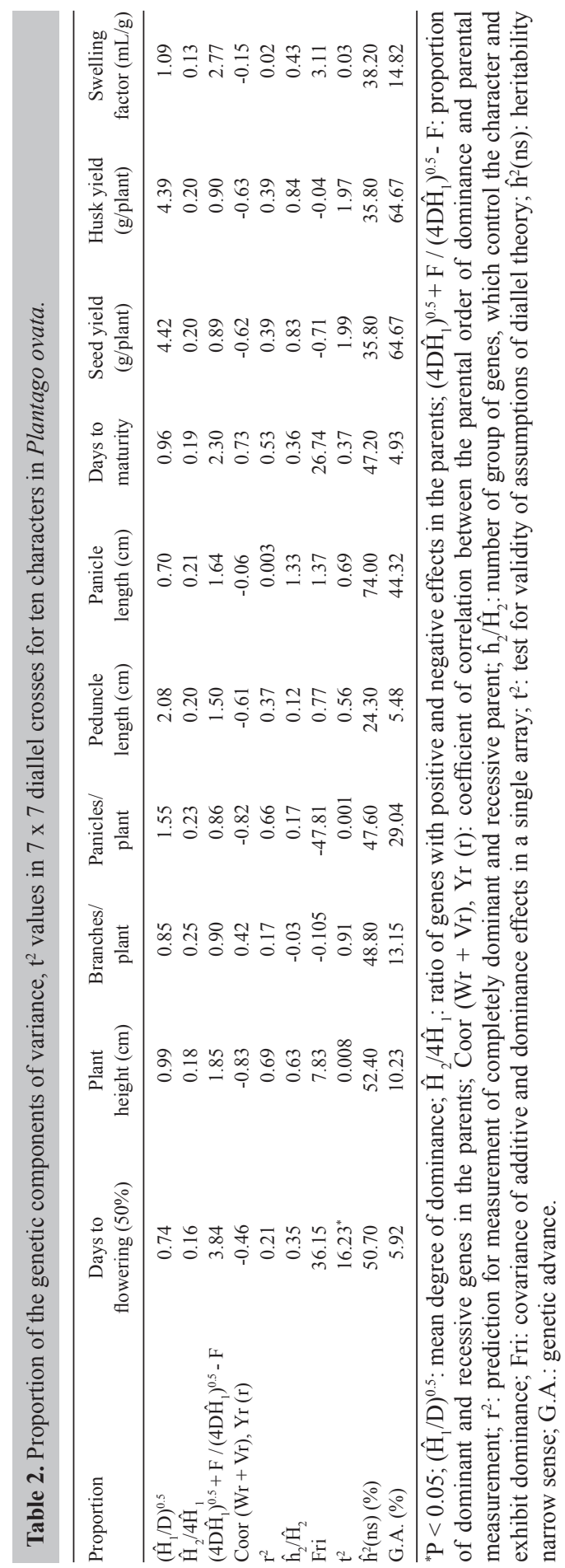


The average level of dominance can be detected by the nature (+ or -) and magnitude of the Y-intercept, which indicates the point on the Wr-axis (in $\mathrm{Wr}-\mathrm{Vr}$ graph), where the regression line intercepts the $\mathrm{Wr}$-axis in relation to the origin, 0. For plant height and seed yield, the regression line intercepted the Wr-axis below the origin, i.e., $a<0$ (negative), suggesting the presence of over dominance. For branches/plant and panicles/plant, the regression line intercepted the $\mathrm{Wr}$-axis above the origin, i.e., a $>0$ (positive), suggesting the presence of partial dominance. Further, the entire parent array points were scattered along the regression line, showing wide genetic diversity among parents (Figure 2A-D).
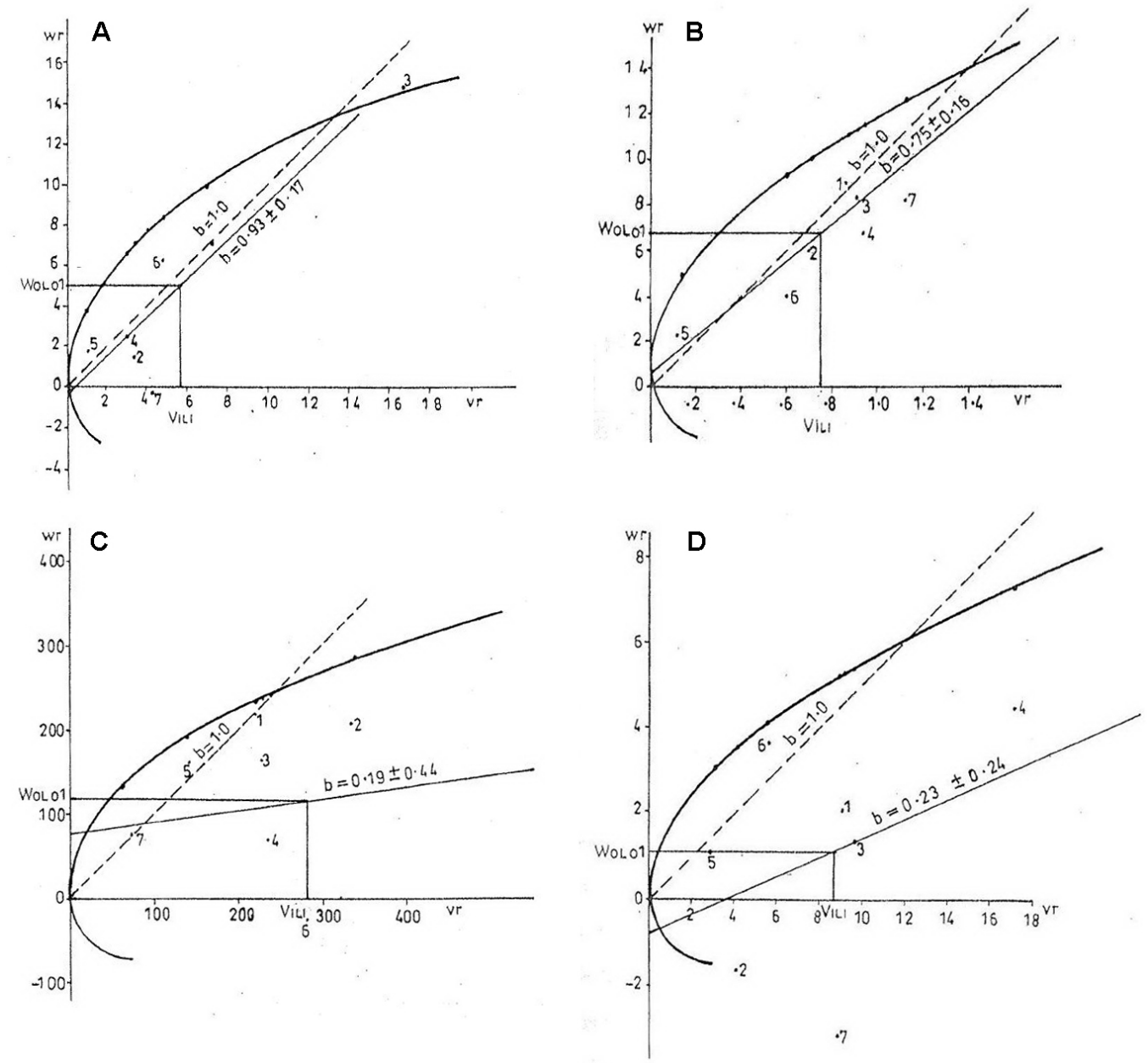

Figure 2. A. Wr - Vr graph for plant height. B. Wr - Vr graph for branches/plant. C. Wr - Vr graph for panicles/ plant. D. Wr - Vr graph for seed yield. 


\section{DISCUSSION}

The genus Plantago (family: Plantaginaceae) comprises 200 species, of which 10 occur in India (Anonymous, 1969). Among the latter, Plantago ovata $\mathrm{F}$ is valued for its seeds and husk, which have been used in indigenous medicine for many centuries all over the world (Figures 3,4).

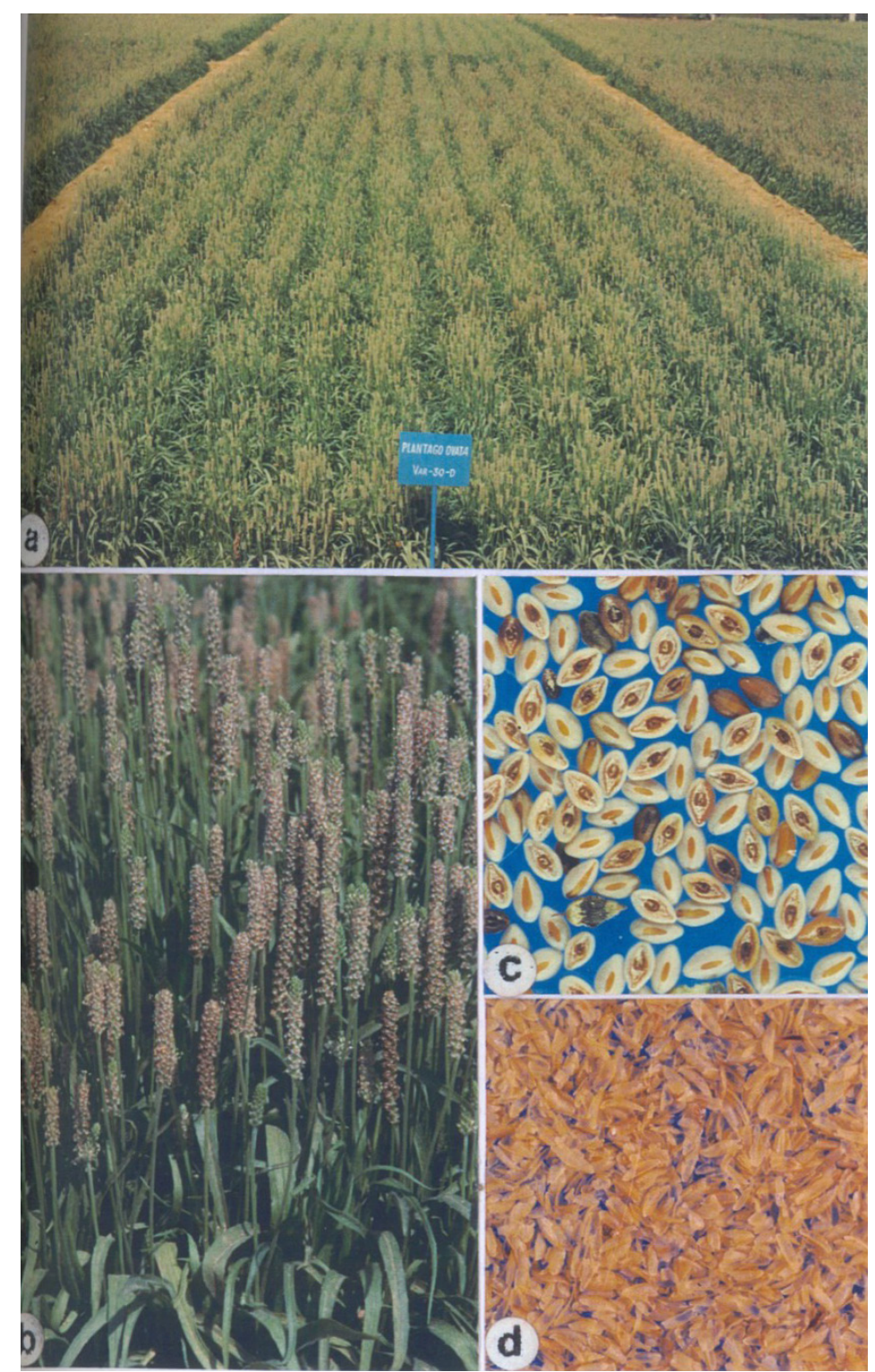

Figure 3. a. Field view of Plantago ovata. b. Close up of $P$. ovata. c. Seeds of $P$. ovata. d. Husk of $P$. ovata. 


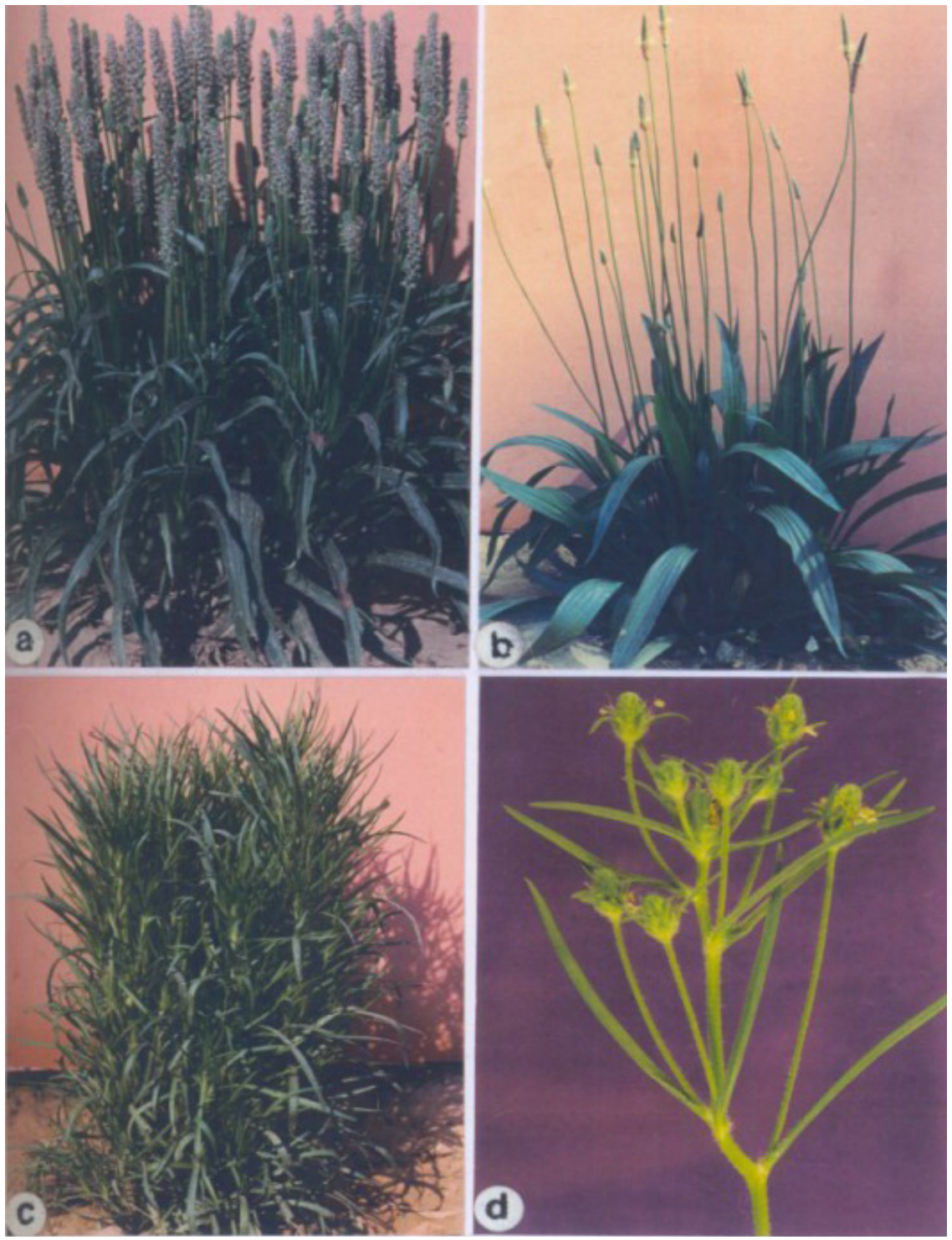

Figure 4. a. Single plant of Plantago ovata. b. Single plant of $P$. lanceolata. c. Single plant of $P$. major. d. Inflorescence of $P$. major showing panicles.

The seeds and husk of $P$. ovata are used in both traditional and modern medicine. Seeds are used for cooling, as a demulcent, in inflammatory and bilious derangement of the digestive organs, applied as a poultice to rheumatic and gouty swellings, in dysentery and for irritation of the intestinal tract; the decoction is used for cough and chronic diarrhea. The husk from the seed has the property of absorbing and retaining water, and hence, it works as an anti-diarrheal drug. 
The variations among genotypes, not only for the primary metabolic products, such as amino acids, proteins, starch, etc., leading to morphological characteristics of plants, occur due to more than one factor. The degree of out-crossing is one such potent factor. However, it varies over genotypes and their genetic makeup, environments (G X E interactions) and honeybee activity. Though the majority of genotypes are predominantly self-pollinating, cross-pollination ranges from 10 to $70 \%$ in some genotypes, depending on genetic and non-genetic causes.

In isabgol, the plant continues to synthesize primary metabolites expressed in the form of the traits. The capacity for such character expression is highly variable from genotypes to genotypes. The other factor in the crop is the seeds propagated. Farmers grow a small quantity of these seeds resulting in considerable genetic drift. Obviously, this leads to possible loss of many alleles under domestication. This, therefore, causes variation from year to year, even if the same lot of seeds is utilized. Besides, isabgol has been cultivated for centuries in India. However, human interferences, selection, spontaneous mutations, genetic drift, and gene flow for productive types have by and large been minimal.

Its diverse ecological adaptations from Gujrat, Rajasthan, Madhya Pradesh, Bihar, Uttar Pradesh, and Haryana States of India seem to have created a number of local landraces. Such a variation would arouse considerable interest among breeders in resorting to selection practices.

As a matter of fact, the crop has hitherto remained virgin, as far as its genetic improvement is concerned. Only recently, some varieties, for instances, Niharika and Mayuri at the Central Institute of Medicinal and Aromatic Plants, Lucknow, India and Gujrat isabgol - 1, 2 and $\mathrm{H} 1$, have been released by some other institutes for cultivation in respective isabgol growing tracts (Lal et al., 1999).

Empirically, it is often propounded that the breeding procedure for crop improvement is dependent on the crossing behavior of the material in hand. However, recent awareness tends to modify such a belief: it says that though the mating system is important in facilitating the application of breeding procedures, the application of breeding principles goes beyond the mating system. In other words, the nature of gene action and prevailing variance components are equally important for crop improvement as is the mating system. In this backdrop, the nature of the genetic variance component and type of gene actions were determined in the present investigation.

The significance of both additive component $\left({ }^{\wedge} \mathrm{D}\right)$ and dominance component $\left(\hat{\mathrm{H}}_{1}\right)$ for all characters except panicles/plant demonstrated that the expression of these characters was conditioned by both additive and dominance genes. Both additive and dominance components were also found to be significant for biomass and crude drug yield in Hyoscyamus niger (Sharma et al., 2000). Seed yield and husk yield were significant only for the dominance component. Lal and Sharma (1999) also observed the importance of only the dominance component for seed yield in opium poppy. This suggested the importance of both additive and non-additive components. Seed yield and husk yield were significant only for the dominance component. The regression line for seed and husk yield was below the origin indicating the presence of over dominance. The overall dominance effect $\left(\hat{h}_{2}\right)$ suggested that substantial heterozygosity in the parents was present for the traits plant height, panicle length, seed and husk yield, showing significant $\hat{h}_{2}$ estimates, and was not significant for others. The symmetry of distribution of dominant and recessive alleles in parents indicated $\mathrm{F}>0$ for days to flowering $50 \%$, plant height, peduncle length, panicle length, days to maturity, and swelling factor, thereby meaning a prevalence of dominant alleles, whereas $\mathrm{F}<0$ for branches/plant, panicles/plant, and seed and husk 
yield means recessive alleles were more prevalent than dominant alleles for these characters. Further observations revealed that dominance variation accrued mainly from over dominance for the characters having a potence ratio $\left(\hat{\mathrm{H}}_{1} / \mathrm{D}\right)^{0.5}>1$, whereas partial dominance was operative for the characters showing $\left(\hat{\mathrm{H}}_{1} / \mathrm{D}\right)^{0.5}<1$. Proportions of genes $\left(\hat{\mathrm{H}}_{2} / 4 \hat{\mathrm{H}}_{1}\right)$ with positive and negative effects at the loci, which showed dominance, were nearer to symmetry for branches/ plant, panicles/plant, and panicle length. This suggests that if parents are chosen at random from a group of phenotypically analogous sources for these characters, it is expected that the desired genes whether positive or negative, have equal chance of being sampled. Characters showing a proportion of dominant and recessive genes greater than unity showed an excess of dominant alleles and a minority of recessive alleles, but the value less than one means a minority of dominant alleles and excess of recessive alleles. This was also proved by the positive and negative direction of the F-estimates. The estimates of $\hat{\mathrm{h}}_{2} / \hat{\mathrm{H}}_{2}$ for the characters studied in the present study ranged from -0.03 to 1.33 . The estimates were less than one for all the characters except panicle length, most likely underestimated. This may be attributed to unequal effects of dominant genes in intensity and dependent on their direction as well as cancellation effects. According to Jinks (1954), non-random distribution of the genes may bring about this discrepancy. The lower values of the estimate would not mean an absence of genes exhibiting dominance for the characters, as this estimate has no connection with Mather's (1949) definition of effective factors (Hayman, 1954a,b). Hayman's graphic approach to diallel analysis is based on a monogenic additive model. Hence, the first requirement is to test the adequacy of this model by detecting whether non-allelic interaction (epistasis) is present or absent. The non-significance of $\mathrm{t}^{2}$ for all the characters indicated validity of the hypothesis postulated by Hayman (1954b). The over-dominance type of gene action was involved in the inheritance of plant height and, seed and husk yield, which can be utilized for the development of hybrid varieties. Similar results have been found in cotton (Mukhtar et al., 2000) and wheat for grain yield/plant (Dere and Yildirim, 2006). Partial dominance was observed in the inheritance of branches/plant and panicles/plant. Xu and Shen (1991) also reported partial dominance for tiller number in rice._

The regression lines for plant height, seed and husk yield were below the origin, indicating the presence of over-dominance, while for branches/plant and panicles/plant it was above the origin, suggesting, the presence of partial dominance. Heritability in the narrow sense is a very useful selection parameter in plant breeding. In the present study, it was very high for panicle length, days to floweing, medium for plant height, branches/plant, panicles/plant, days to maturity, seed yield, husk yield, and swelling factor. However, genetic advance was high for panicle length, seed yield and husk yield. Thus, as the Plantago ovata crop is predominantly selfpollinating but reflecting up to $70 \%$ cross-pollination, it can be genetically manipulated in more than one way depending on the nature of gene action, heritability and genetic advance, prevalent in the material in hand/genetic stocks. In view of impressive genetic components (additive - ${ }^{\wedge} \mathrm{D}$, and dominance $-\hat{H}$ ), heritability and genetic advance displayed by many hybrids for important traits such as seed and seed husk yield, in combination with that for agronomic traits, such as plant height and days to flowering (50\%), hybrid development may be a rewarding proposition even in the absence of suitable male sterile lines in Plantago ovata. Based on these genetic information in this study, hybridizations, isolation of superior genotypes by sib selection and recurrent selection, and exploitation of hybrid vigor in specific parents cross-combinations have been suggested for isabgol crop improvement. This can lead to population improvement where the presence of significant reciprocal effects would not have much of a role to play. 


\section{CONCLUSIONS}

The additive component $\left({ }^{\wedge} \mathrm{D}\right)$ of genetic variance was significant for days to flowering, plant height, branches/plant, peduncle length, panicle length, days to maturity, and swelling factor, whereas the dominance component $\left(\hat{\mathrm{H}}_{1}\right)$ of genetic variance was significant for all the characters except panicles/plant. $\mathrm{t}^{2}$, the test of additivity, was not significant for all the characters indicating absence of non-allelic interactions (epistasis) in controlling gene expression. Heritability in the narrow sense is a very useful selection parameter in plant breeding. In the present study, it was very high for panicle length, days to flowering, medium for plant height, branches/plant, panicles/plant, days to maturity, seed yield, husk yield, and swelling factor. However, genetic advance was high for panicle length, seed yield and husk yield related to economic traits. Based on these genetic information in this study, hybridizations, isolation of superior genotypes by sib selection and recurrent selection, and exploitation of hybrid vigor in specific parent cros-combinations are suggested for isabgol crop improvement.

\section{REFERENCES}

Allard RW (1960). Principles of Plant Breeding. John Wiley and Sons Inc., New York, 92-102.

Anonymous (1969). The Wealth of India. Raw Materials, VIII. Ph-RC. Publications and Information Directorate. Council of Scientific and Industrial Research, New Delhi, 146-154.

Dere S and Yildirim MB (2006). Inheritance of grain yield per plant, flag leaf width, and length in an $8 \times 8$ diallel cross population of bread wheat (T. aestivum L.). Turk. J. Agr. Forest 30: 339-345.

Hayman BI (1954a). The analysis of variance of diallel tables. Biometrics 10: 235-244.

Hayman BI (1954b). The theory and analysis of diallel crosses. Genetics 39: 789-809.

Hayman BI (1958). The separation of epistatic from additive and dominance variation in generation means. Heredity 12: 371-390.

Jinks JL (1954). The analyses of continuous variation in a diallel cross of Nicotiana rustica varieties. Genetics 39: 767-788.

Lal RK and Sharma JR (1999). Inheritance and influence of developmental traits on seed yield in opium poppy (Papaver somniferum). J. Med. Aromat. Plant. Sci. 21: 1079-1084.

Lal RK, Sharma JR and Mishra HO (1999). Induced variability and varietal selection in isabgol (Plantago ovata). J. Med. Aromat. Plant. Sci. 2: 34-37.

Mather K (1949). Biometrical Genetics. Dover Publication, Inc., New York.

Mukhtar LMS, Khan TM, Khan AS, Khan MA, et al. (2000). Diallel analysis of some important fibre characteristics of Gossypium hirsutum L. Int. J. Agri. Biol. 2: 261-263.

Sharma JR (1998). Statistical and Biometrical Techniques in Plant Breeding. New Age International, New Dehli.

Sharma JR, Lal RK, Gupta MM, Misra HO, et al. (2000). Inheritance of biomass and crude drug content in black henbane (Hyoscyamus niger L.). J. Herb Spices Med. Plant 7: 75-84.

Singh RK and Chaudhary BD (1979). Biometrical Methods in Quantitative Genetic Analysis. Kalyani Publishers, New Delhi. Xu YB and Shen ZT (1991). Diallel analysis of tiller number at different growth stages in rice (Oryza sativa L.). Theor. Appl. Genet. 83: 243-249. 